\title{
UTILIZAÇÃO DAS TECNOLOGIAS ASSISTIDAS NA CONCEPÇÃO, NO DESENVOLVIMENTO E NO PROJETO DE UMA ESCOVA DENTAL SUSTENTÁ VEL E ERGONÔMICA
}

\author{
Letícia Alcará da Silva ${ }^{1}$, Augusto Seolin Jurisato ${ }^{2}$, Luiz Antonio Vasques Hellmeister ${ }^{3}$
}

\begin{abstract}
The toothbrush is identified as one of the most importants inventions in human history. Most of them are made by polypropylene, a recyclable polymer. Some are made of polypropylene and polyethylene leftovers from others industrial processes. However, the toothbrushes are discarded incorrectly and end up in landfills, which could be avoided by using a material and design suitable for the manufacture of the product. This study aimed, based on research, develop and design a toothbrush model with great features. For the conception of the prototype, was used rapid prototyping technologies. With the intention of improving the product quality, was created an ergonomic, sustainable and environmentally friendly model, seeking maximally reduce the generation of waste and environmental damages. The solution adopted was the use of "interchangeable head", which can be discarded after their useful life, keeping the rest of the body.
\end{abstract}

Index Terms - Design, toothbrush, sustainability, rapid prototyping, CNC, bamboo.

\section{INTRODUÇÃO}

As primeiras ferramentas de higienização bucal surgiram em torno de 3500 a.C.. Eram palitos com as extremidades desgastadas, feitos a partir de galhos de árvores, utilizados pelos egípcios e babilônios. Acredita-se que os chineses foram os criadores da escova dental, por volta do século XV. As cerdas eram pelos de porco presas a um osso ou a um pedaço de bambu, que faziam a vez do corpo da escova. Em 1780, o inglês William Addis foi o precursor da produção em massa de escovas "modernas": o corpo era esculpido a partir de ossos de gado e as cerdas eram pelos de porco, mas depois substituídas por pelos de vaca e javali, que eram mais suaves. As cerdas de nylon foram introduzidas somente em 1938, sendo o melhor material para a confecção de cerdas de escovas (Figura. 1).

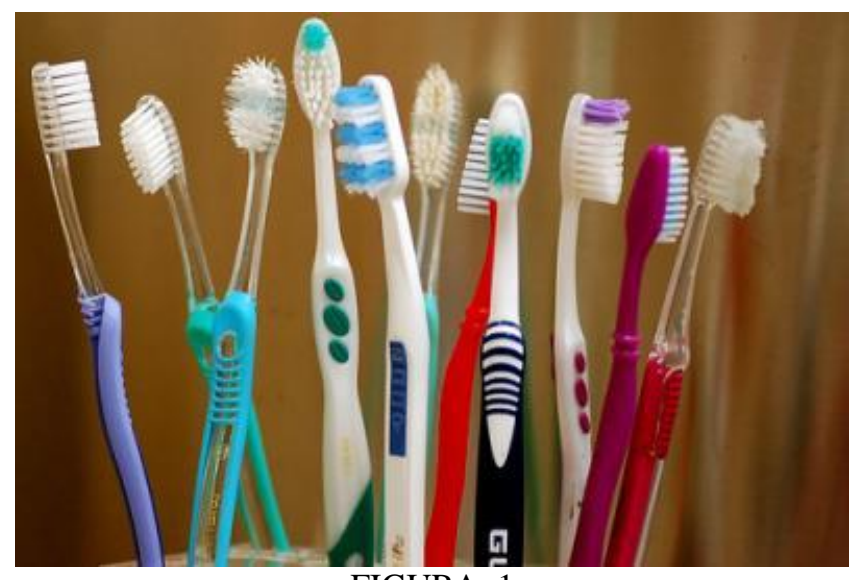

FIGURA. 1

MODELOS DE ESCOVAS DENTAIS.

A escova dental foi apontada como um dos mais importantes inventos da história da humanidade. Grande parte delas é feitas de polipropileno, um polímero reciclável. Algumas são feitas de sobras de polipropileno e polietileno provenientes de outros processos industriais. Porém, mesmo sendo recicláveis, as escovas são descartadas de forma incorreta e acabam em aterros sanitários. Isso poderia ser evitado, se as empresas mudassem o design e o material utilizado para a confecção do produto.

Para a concepção do produto, foi utilizado o método da prototipagem rápida $(\mathrm{RP})$. O protótipo de um produto ou componente é a parte essencial no seu processo de desenvolvimento, pois possibilita que a análise de sua forma e funcionalidade seja feita numa fase anterior a produção de ferramental definitivo. Historicamente, as representações físicas dos produtos (ou simplesmente protótipos) vêm sendo utilizadas desde a antiguidade, evoluindo de manuais, ainda bastante utilizadas, para protótipos virtuais nos anos 80 , com a disseminação dos sistemas CAD (Computer Aided Design) tridimensionais, e mais recentemente com os protótipos rápidos.

A RP pode ser definida como um processo de fabricação através da adição ou remoção de material em forma de camadas planas sucessivas, isto é, baseado no princípio da manufatura por camada. Esta tecnologia permite

\footnotetext{
${ }^{1}$ Letícia Alcará da Silva, Discente do Curso de Design, Faculdade de Arquitetura, Artes e Comunicação, FAAC-UNESP, Av.Eng ${ }^{\circ}$ Luiz Edmundo Carrijo Coube 14-01, Vargem Limpa, Bauru, SP, Brazil, lehalcara@gmail.com

${ }^{2}$ Augusto Seolin Jurisato, Discente do Curso de Engenharia Mecânica, Faculdade de Engenharia de Bauru, FEB-UNESP, Av.Eng ${ }^{\circ}$ Luiz Edmundo Carrijo Coube 14-01, Vargem Limpa, Bauru-SP. as.jurisato@live.com

${ }^{3}$ Luiz Antonio Vasques Hellmeister, Professor Doutor, DARG-FAAC-UNESP, Av.Eng ${ }^{\circ}$ Luiz Edmundo Carrijo Coube 14-01, Vargem Limpa, Bauru-SP. hellmeister@faac.unesp.br
} 
fabricar componentes (protótipos, modelos, etc.) físicos em três dimensões (3D), com informações obtidas diretamente do modelo geométrico gerado no sistema CAD, de forma rápida, automatizada e totalmente flexível. [1]

\section{OBJeTIVos}

O objetivo é, com base em estudos, desenvolver e projetar um modelo de escova dental com características ótimas, mais adequadas para a higienização bucal, segundo estudos realizados por BASS (1954). Ele preconizou as características ideais da escova dentária com cerdas de nylon para o adulto: o cabo deveria ser reto e plano em relação à parte ativa (cabeça); o comprimento total da escova seria de cerca de 152,4 $\mathrm{mm}$ (6 polegadas), com largura de 11,116 mm (7/16 de polegada); a parte ativa deveria comportar três fileiras, com seis tufos de cerdas em cada uma das fileiras (18 tufos no total), distribuídos simetricamente e contendo cada um deles de 80 a 86 filamentos de cerdas; cerdas de nylon macio de alta qualidade com $0,18 \mathrm{~mm}(0,007$ de polegada) de diâmetro e com comprimento de $10,318 \mathrm{~mm}$ (13/32 de polegada); e pontas desgastadas e acabadas de forma hemisférica ou pelo menos o bastante para eliminar todas as pontas cortantes e ângulos grosseiros (arredondados). [2]

Para a concepção do protótipo, foram utilizadas tecnologias de prototipagem rápida. Com o intuito da melhoria da qualidade do produto, foi criado um modelo ergonômico, sustentável e ecologicamente correto, buscando diminuir ao máximo a geração de resíduos e danos ao meio ambiente.

\section{METOdOLOGIA E MATERIAIS}

Primeiramente foram desenvolvidos diversos sketches manuais, até se chegar à forma desejada da escova dental, sempre pensando na ergonomia e sustentabilidade. Após a escolha da forma, o projeto da escova foi reproduzido nos softwares de projeto assistido por computador - CAD, Solid Edge ST5 (para a concepção das peças) e Solid Works 2013 (para a junção das peças e rendering). Foram também estabelecidas as três dimensões nas quais a peça seria usinada e foi feito um rendering para uma visualização de como o projeto ficará (Figura. 2).

Após diversas pesquisas, chegamos à conclusão de que o material mais sustentável e ecológico que poderia ser utilizado é o bambu.

O bambu possui excelentes características biológicas, físicas, químicas e mecânicas que o habilitam a ser utilizado em numerosas aplicações práticas. A literatura nos mostra mais de 1000 diferentes usos para o bambu, desde alimento através de seu nutritivo broto até casas, móveis, instrumentos musicais, artesanatos, ferramentas e utensílios diversos.

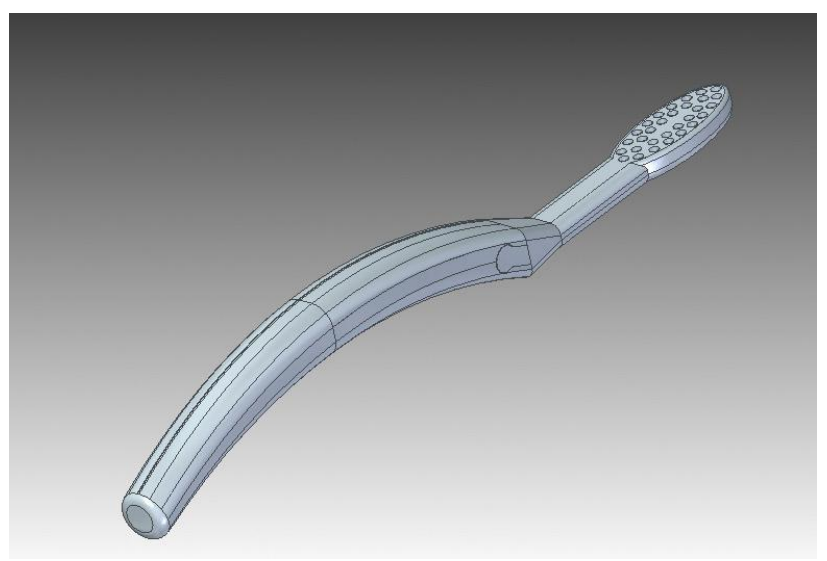

FIGURA. 2

CONCEPÇÃO DA MODELAGEM VIRTUAL TRIDIMENSIONAL NO SOFTWARE SOLID EDGE.

Algumas aplicações industriais com o bambu tem sido atualmente objeto de pesquisas e desenvolvimento prático, podendo-se destacar possibilidades de exploração como Agroindústria, tais como: fábrica de polpa e celulose para papel, fábrica de móveis, fábrica de artesanatos, fábrica para pisos e cabos de ferramentas à base de bambu laminado colado (BLC), fábrica de casas populares, fábrica de brotos (responsável por U\$\$ bilhões/ano de exportação na China).

$\mathrm{Na}$ área ambiental, o bambu é considerado o "amigo da natureza", pois ao lado de ser um grande protetor do solo, devido ao seu vigoroso sistema radicular, é um rápido sequestrador e armazenador de carbono, fornece alimento e abrigo para a vida selvagem, é um recurso perene, renovável e de crescimento muito rápido (seis meses entre o nascimento do broto e a altura final do colmo, que pode atingir até 30 metros em algumas espécies gigantes) e ainda pode ser utilizado em milhares de aplicações, tudo isto, utilizando-se apenas da energia do sol como alimento (fotossíntese).

A falta de cultura a respeito faz o bambu ser esquecido e desconhecido entre nós, porém é referenciado até como divindade entre os orientais, tendo acompanhado a história do homem desde tempos imemoriais.

Existem no mundo cerca de 1300 espécies de bambu, a maioria delas, espécies tropicais que se adaptam muito bem às nossas condições, como tem sido observado em pesquisas conduzidas para a introdução de espécies prioritárias na Área Experimental Agrícola do Departamento de Engenharia Mecânica da UNESP/Campus de Bauru, onde também, no seu Laboratório de Processamento de Materiais, estão sendo desenvolvidas pesquisas com "bambu laminado colado e sarrafeado", o que inclui aplicações como, pisos, forros, paredes, cabos de ferramentas, vigas e vigotas para construção.

\section{Bambu Laminado Colado (BLC)}

O material escolhido para a execução do projeto foi o BLC (Figura. 3). 
Talvez essa seja a aplicação mais promissora para o bambu, pois alia a possibilidade de agregar valor à grande quantidade de produtos que podem ser confeccionados com este material, podendo substituir em muitos casos a utilização das madeiras.

A escassez de madeiras tradicionais fatalmente levará o Brasil à racionalização no emprego de seus recursos naturais. Com o crescente desmatamento e o aumento da pressão sobre as florestas tropicais, bem como sobre as áreas de reflorestamento, torna-se cada vez mais necessária a busca por materiais renováveis e por soluções alternativas capazes de atenuar em parte este processo. Produtos à base de bambu laminado colado, tais como pisos, chapas, painéis, cabos para ferramentas manuais ou agrícolas, compensados, móveis, componentes da construção civil, indústria moveleira, entre outros, são possíveis de serem obtidos por meio do processamento do colmo.

Muito embora o bambu seja utilizado e estudado há séculos nos países orientais (China Bamboo Research Center-CBRC, 2001), destaca-se que a partir dos anos 80 tem ocorrido uma intensificação do uso do bambu em diversas áreas industriais. Dentre elas destacam-se a aplicação em alimentos, papel, engenharia, química e produtos à base de bambu processado (madeira de bambu), as quais podem substituir e/ou evitar o corte e o uso de florestas tropicais. Podem ser obtidos produtos tais como: carvão, carvão ativado, palitos, chapas, painéis, produtos à base de bambu laminado colado (BLC), esteiras, compósitos, chapas de fibra orientada (OSB), componentes para construção/habitação e para a indústria moveleira, dentre outros.

Dessa maneira torna-se muito promissor o desenvolvimento de produtos à base de bambu laminado colado, tanto pelo fato de ser um produto advindo de material renovável, que poderia aliviar a pressão sobre florestas, como pela sua estética e ainda pela sua aceitação no mercado internacional.

Para o bambu laminado colado (BLC), poucos estudos foram desenvolvidos no Brasil (CARRASCO et al., 1995; GONÇALVES et al., 2002; BERALDO \& ABBADE, 2003; PEREIRA, 2006a). A maior dificuldade observada pelos autores refere-se à ausência de equipamentos que permitam usinar adequadamente o bambu, transformando-o de um tubo de parede delgada e, ripas de seção regular.

Estudos desenvolvidos por Beraldo \& Abbade (2003) evidenciam que as características físicas e mecânicas do BLC são plenamente favoráveis à utilização desse material na indústria do mobiliário e na confecção de utensílios domésticos.

Foram estudados BLC combinando-se duas espécies de bambu (D. giganteus e B. vulgaris) com dois tipos de adesivos comerciais (Cascophen e Cascamite). Os colmos foram transformados em taliscas ou ripas as quais foram submetidas ao tratamento químico por imersão, visando a aumentar sua vida útil.
Posteriormente, com o auxílio de uma lâmina metálica, efetuou-se a retirada das camadas interna e externa (ambas refratárias ao adesivo). $\mathrm{O}$ acabamento das peças foi efetuado em uma desengrossadeira. $\mathrm{O}$ adesivo foi distribuído com pincel ao longo de uma das faces de cada lâmina. A seguir, procedeu-se à prensagem do BLC; um dispositivo permitiu efetuar a retirada do BLC logo após a prensagem, por meio de travamento do conjunto com parafusos. [3]

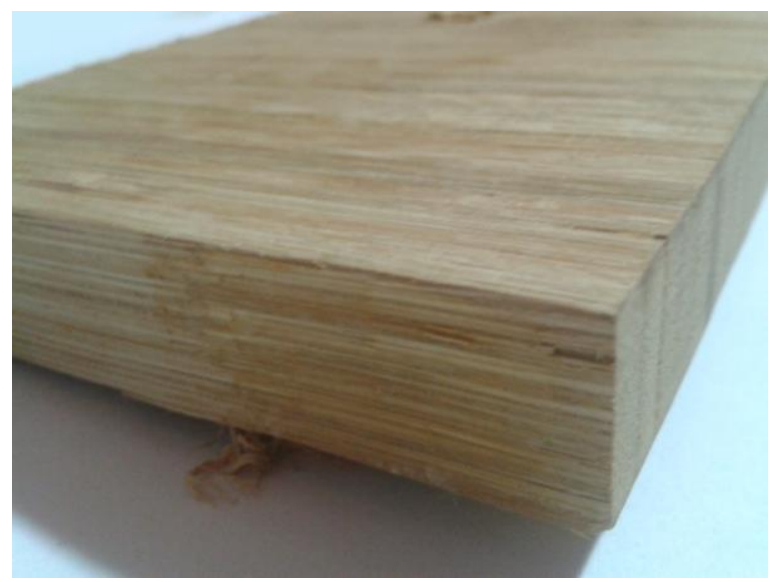

FIGURA. 3

AMOSTRA DE BAMBU LAMINADO COLADO.

\section{Máquina Fresadora}

Para a concepção do modelo, foi utilizada uma máquina fresadora CNC (Computer Numeric Control - Controle Numérico Computadorizado) projetada e construída por alunos do curso de engenharia mecânica da UNESP de Bauru em anos anteriores. Através de um trabalho concluído pelo grupo diz-se que a máquina está aferida. Amostras de MDF (Medium Density Fiber) foram usinadas com uma fresa de topo Bosch de duas lâminas de corte e $6,35 \mathrm{~mm}$ de diâmetro rotacionada por uma retífica modelo Makita GD08000C. A Figura. 4 mostra o conjunto montado na máquina fresadora construída.

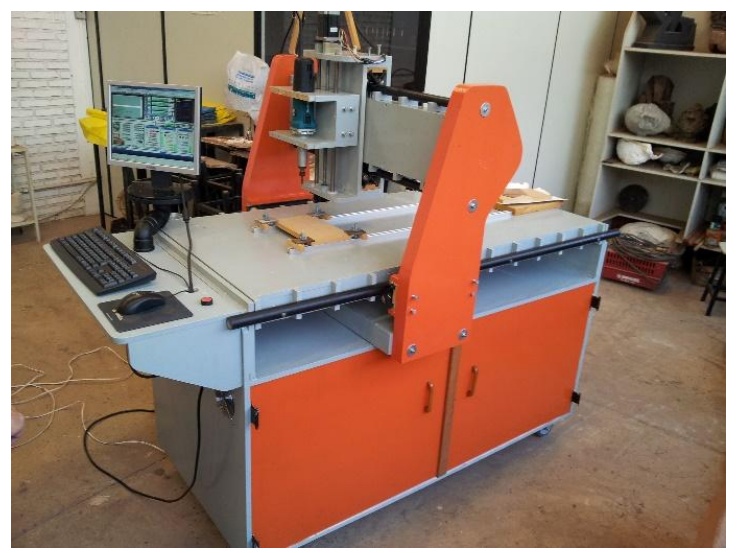

FIGURA. 4

MAQUINA FRESADORA CNC DESENVOLVIDA NA UNIVERSIDADE. CONJUNTO MONTADO E PRONTO PARA USINAGEM. 


\section{RESULTADOS}

\section{Cabeça Intercambiável}

Para a redução de resíduos gerados pelo descarte da escova, foi pensado um modelo de escova dental no qual o corpo e a parte ativa (cabeça) são encaixados um ao outro, possibilitando a sua separação, como é mostrado na Figura. 5. Dessa forma, apenas a cabeça será descartada após o fim de sua vida útil, evitando o descarte desnecessário do corpo, que fica intacto.

Além de evitar a geração de resíduos, o objetivo do encaixe é ser prático e de fácil junção entre as partes.

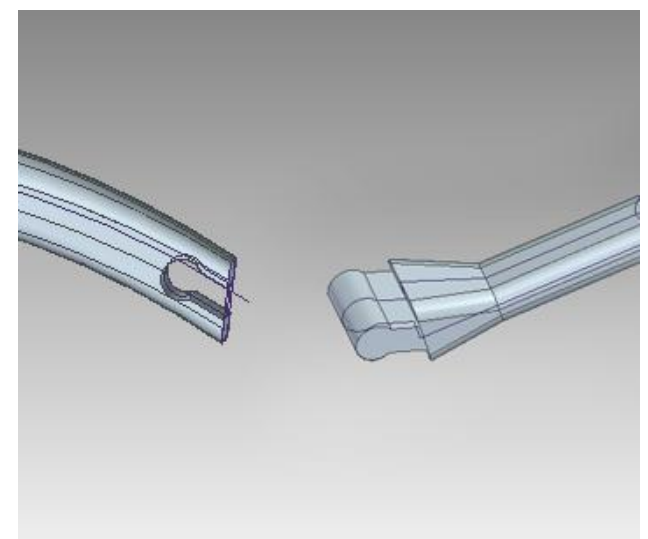

FIGURA. 5

DETALHE DO ENCAIXE ENTRE O CORPO E A CABEÇA NO SOFTWARE SOLID EDGE.

\section{Forma da Escova}

A forma foi desenvolvida pensando sempre nos princípios da ergonomia. Foram realizados diversos sketches manuais considerando a "pega" da mão na escova até chegar à forma desejada, que seja segura, eficiente e satisfaça o usuário (Figura. 6).

Para isso, foi desenvolvido um corpo possui um formado que "encaixa" na mão do usuário.

Foi feito o modelo de tamanho real nos softwares CAD, onde foram estabelecidas as três dimensões nas quais a peça seria usinada, e também os detalhes geométricos.

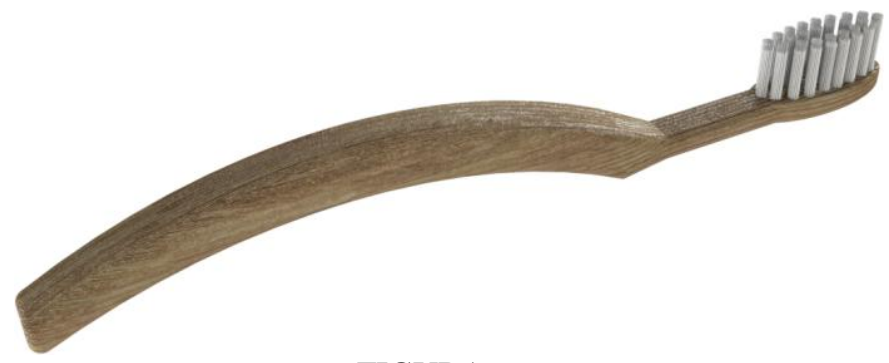

FIGURA. 6

ESCOVA DENTAL RENDERIZADA NO SOFTWARE SOLID WORKS.

\section{Código G}

Uma vez que o modelo tridimensional estava pronto, esse foi elevado para a próxima fase de produção, o estudo e programação do código $\mathrm{G}$ capaz de compreender os detalhes da geometria criada e aperfeiçoar a usinagem através da conversão em linguagem de máquina do modelo virtual. Para isso foi utilizado o software ArtCAM trial de manufatura assistida por computador - CAM (Computer Aided Manufacturing - Manufatura Auxiliada por Computador). Apesar de se tratar de uma versão trial, esse software possibilitou os primeiros testes de usinagem do modelo real da escova.

\section{Usinagem}

A primeira usinagem foi realizada na máquina fresadora CNC (Figura. 7), que dispõe de três motores de passos, que compreendem os três eixos coordenados, controlados por um sistema computadorizado e que é responsável por transformar cada código gerado pelo software CAM em seu devido movimento de usinagem. Como os movimentos retilíneos e curvilíneos. Por se tratar de um código padronizado, não existiu a necessidade de convertê-lo para outro sistema, e o software responsável por isso foi o LinuxCNC - versão do sistema operacional Linux voltado para usinagem $\mathrm{CNC}$.

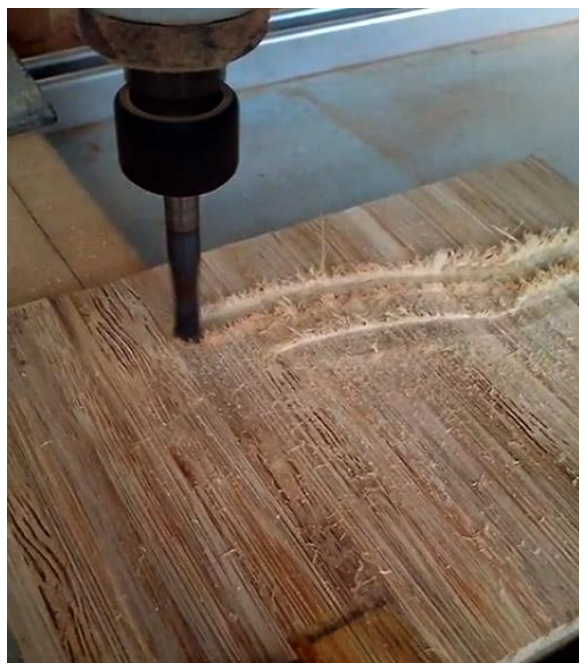

FIGURA. 7

PRIMEIRO TESTE DE USINAGEM DO BLC

\section{Finalização}

Após a usinagem das partes, foram feitos testes com os encaixes e alguns pequenos ajustes.

Para maior conservação do corpo da escova dental, foi aplicado o verniz Epoxi, que é não tóxico e a prova d'água.

As cerdas escolhidas para a parte ativa da escova são de nylon macio de alta qualidade, já mencionado nos objetivos, 
com 0,18 mm de diâmetro e com comprimento de 10,318 $\mathrm{mm}$ e com as pontas arredondadas.

\section{CONCLUSÃo}

Concluiu-se que a utilização das tecnologias assistidas por computador são acessíveis e eficazes na concepção, modelagem e usinagem de produtos, em especial, escovas dentais, atendendo suas peculiaridades, como utilização de materiais alternativos e sua relação com a sustentabilidade. Pode-se inclusive simular através dessas tecnologias, o principal objeto do estudo, que é o encaixe entre a cabeça intercambiável e o corpo permanente.

\section{Agradecimentos}

Agradecimentos especiais ao grupo Bambu Taquara da UNESP/Bauru, por compartilhar o conhecimento sobre os processos da preparação do BLC e por ceder o material para usinagem. Agradecimentos também ao Paulo Bustamante da Bambuzeria, que desenvolve pesquisas sobre tratamentos do bambu e recomendou o uso do verniz Epoxi, ao Evandro Ferreira de Alcântara pelo auxílio e a Faculdade de Arquitetura, Artes e Comunicação - FAAC/Unesp Bauru, pela montagem e disponibilização da máquina CNC no Departamento de Artes e Representação Gráfica DARG/Unesp Bauru.

\section{REFERENCIAS BIBLIOGRÁFICAS}

[1] VOLPATO, N. "Prototipagem Rápida - Tecnologias e Aplicações", São Paulo: Editora Blücher, 2007.

[2] MIZUNO, E., H. F., "Comparação entre duas técnicas de escovação e dois tipos de dureza de cerdas de escovas dentais manuais na efetividade da higienização bucal", Dissertação (Mestrado em Odontologia) - Faculdade de Odontologia de Bauru, Universidade de São Paulo, Bauru. 2003.

[3] PEREIRA, M. A. R., BERALDO, A. L., "Bambu de corpo e alma". São Paulo: Canal 6 Projetos Editoriais, 2008.

[4] IIDA, I., "Ergonomia: Ergonomia: Projeto e Produção", São Paulo: Editora Edgard Blücher, 1997. 